\title{
Optimal duration of androgen deprivation therapy following radiation therapy in intermediate- or high-risk non- metastatic prostate cancer: A systematic review and meta- analysis
}

\author{
Frederico Leal ${ }^{1}$, Maximiliano Augusto Novis de Figueiredo ${ }^{1}$, Andre Deeke Sasse ${ }^{1}$ \\ ${ }^{1}$ Universidade Estadual de Campinas, UNICAMP, SP, Brasil
}

\section{ABSTRACT}

Objectives: To investigate current evidence on the optimal duration of adjuvant hormone deprivation for prostate cancer treated with radiation therapy with curative intent. Materials and Methods: A systematic search was performed in electronic databases. Data from randomized trials comparing different durations of hormone blockade was collected for pooled analysis. Overall survival, disease-free survival, disease-specific survival and toxicity were the outcomes of interest. Meta-analyses were performed using random-effects model.

Results: Six studies met the eligibility criteria. For overall survival, the pooled data from the studies demonstrated a statistically significant benefit for longer hormone deprivation (Hazard Ratio 0.84; 95\% CI 0.74 - 0.96). A statistically significant benefit was also found for disease-free survival (Hazard Ratio 0.74; 95\% CI 0.62 - 0.89), and disease-specific survival (Hazard Ratio 0.73; 95\% CI 0.62 - 0.85). Studies with longer blockade duration arm demonstrated greater benefit. Toxicity was low, with no increase in cardiovascular events.

Conclusions: Longer duration of androgen deprivation combined to radiotherapy prolongs OS, DFS and DSS in patients with intermediate and high-risk non-metastatic prostate cancer. However, this evidence is based on trials using older radiation techniques, and further research of combination of androgen deprivation and new RT technologies may be warranted.
\end{abstract}

\section{ARTICLE INFO}

\section{Key words:}

adjuvant androgen deprivation, hormone blockade, metaanalysis, prostate cancer, radiation therapy

Int Braz J Urol. 2015; 41: 425-34

Submitted for publication: August 09, 2014

Accepted after revision: December 18, 2014

\section{INTRODUCTION}

Prostate neoplasm is the most common malignancy affecting men in the World. Several modalities for the treatment of patients with prostate cancer have become well established, including radical prostatectomy, radiation therapy and androgen deprivation therapy. Both radical prostatectomy and external-beam radiation therapy are considered equivalent options in patients with non-metastatic disease, with different risk profiles $(1,2)$.

The prognostic risk group, based on tumor staging, pre-treatment prostate-specific antigen (PSA) levels and Gleason Score, has been shown to predict survival and treatment outcomes (3). For patients with low-risk localized disease, the 10 -year mortality may be as low as $2 \%$. However, patients with intermediate- and high-risk disease 
have a worse prognosis, with mortality rates ranging from $12 \%$ to $40 \%(3,4)$.

Adjuvant and/or neoadjuvant androgenic suppression has been studied in an attempt to improve outcomes in intermediate- and high-risk non-metastatic prostate cancer (5). Several randomized controlled trials (5-8) and systematic reviews $(9,10)$ have reported an improved disease-free and overall survival for radiotherapy combined with androgen blockade compared to radiotherapy alone. Combined treatment with androgen deprivation and radiotherapy has also been shown to be superior to hormonal blockade alone $(11,12)$. The type of hormonal blockade (central, peripheral, or combined) combined to radiation therapy; the timing of treatment (neoadjuvant, adjuvant or both) and duration of deprivation have all varied among trials. While hormonal blockade with gonadotropin-releasing hormone (GnRH) agonists has been shown to improve outcomes (9), peripheral blockade with bicalutamide has not (13). There is evidence that short-term androgen deprivation may also have some benefit in the neoadjuvant setting, both reducing positive margins in patients treated with radical prostatectomy and improving survival in patients treated with radiation therapy (10).

Androgen deprivation with gonadotropin-releasing agents is already a standard of care for intermediate and high-risk localized or locally advanced prostate cancer treated with radiation therapy, but the optimal duration of hormonal deprivation is yet to be defined (10). Establishing a standardized treatment may be important because while hormone deprivation improves survival, it is also associated with AEs like loss of bone density, erectile dysfunction, hot flashes, and increased cardiovascular risk $(14,15)$. Two large randomized controlled trials $(16,17)$ have suggested that a longer course of androgen deprivation (2 to 3 years) may improve outcomes in high-risk patients compared to 6-month adjuvant therapy. However, there is no consensus of how much longer the adjuvant treatment should be, with a recent trial suggesting that adjuvant hormonal treatment could be safely reduced from 36 months to 18 months (18).

Considering the conflicting conclusions of individual trials, we conducted a systematic review with meta-analysis to critically evaluate the existing evidence to support an indication of an optimal strategy for androgen deprivation to combine with external beam radiation therapy in patients with intermediate- or high-risk non-metastatic prostate cancer.

\section{MATERIALS AND METHODS}

A systematic search was performed in electronic databases, including Pubmed/MEDLINE, EMBASE, LILACS, ClinicalTrials.gov, the Cochrane Library, and ASCO meetings abstracts. Two reviewers performed the study selection independently.

Reports of results from prospective randomized clinical trials comparing different durations of androgen blockade were selected for the meta-analysis. Both adjuvant and neoadjuvant hormone deprivation studies were included. There was no restriction as for the radiation dose delivered in each study. Both conventional and conformal radiation therapy were allowed. Studies evaluating only radiotherapy plus hormonal blockade versus radiotherapy alone were excluded, even if subgroup analysis data comparing different androgen deprivation durations has been published. Trials comparing hormonal blockade alone versus radiation therapy (with or without associated androgen deprivation) were also excluded.

The shorter duration of hormonal therapy in each trial was considered its control arm, regardless of what arm was considered control in the original report. The longer duration arm was considered the experimental arm. Differences among the study designs were critically evaluated and used for sensitivity analysis.

Data extraction was performed independently by two reviewers. Disagreements were resolved by discussion and consensus. Overall survival (OS), disease-free survival (DFS), disease-specific survival (DSS), and toxicity were the outcomes of interest. The reported hazard ratios (HR) were used as a measure of survival benefit. For the articles in which the HR was not reported, we calculated estimates by transcription of the survival curves presented as figures in original articles and calculation with a spreadsheet developed by Tierney et al. (19). 
All studies selected were evaluated by the authors for characteristics linked to potential bias. Information about randomization, blinding, allocation concealment, drop-outs, intention-to-treat (ITT) analysis, and funding source was especially evaluated. Eligibility criteria for the studies were also assessed for differences in patient populations among the trials.

Meta-analyses were conducted with RevMan 5.0 software (Cochrane Collaboration's Information Management System). Analyses of data consisted of the HR for time-to-event outcomes, considering a random effect model. The 95\% confidence intervals (CI) were calculated and presented in forest plots. The diamond at the bottom of the plot summarizes the best estimate results (with the width representing its corresponding 95\% CI).

Statistical heterogeneity was evaluated with the chi-square test, and expressed using the $\mathrm{I}^{2}$ index (20). If significant heterogeneity ( $\mathrm{I}^{2}$ in- dex $>50 \%$ ) was identified, a possible explanation was investigated. Differences in eligibility criteria, patient population, and treatment delivered were assessed and discussed.

\section{RESULTS}

From 127 potential studies identified through the search in databases, 11 articles met the inclusion criteria. Of these, five were excluded for duplication, retrospective results or lack of results. Therefore, six studies were selected for the meta-analysis. The data extraction process is represented in Figure-1.

All six studies were centrally randomized. All but one (21) clearly reported pre-established sample size calculation, with alpha and beta errors defined. All studies performed an ITT analysis. Therefore, the risk of biases in these trials was considered low.

Figure 1 - Flow Chart.

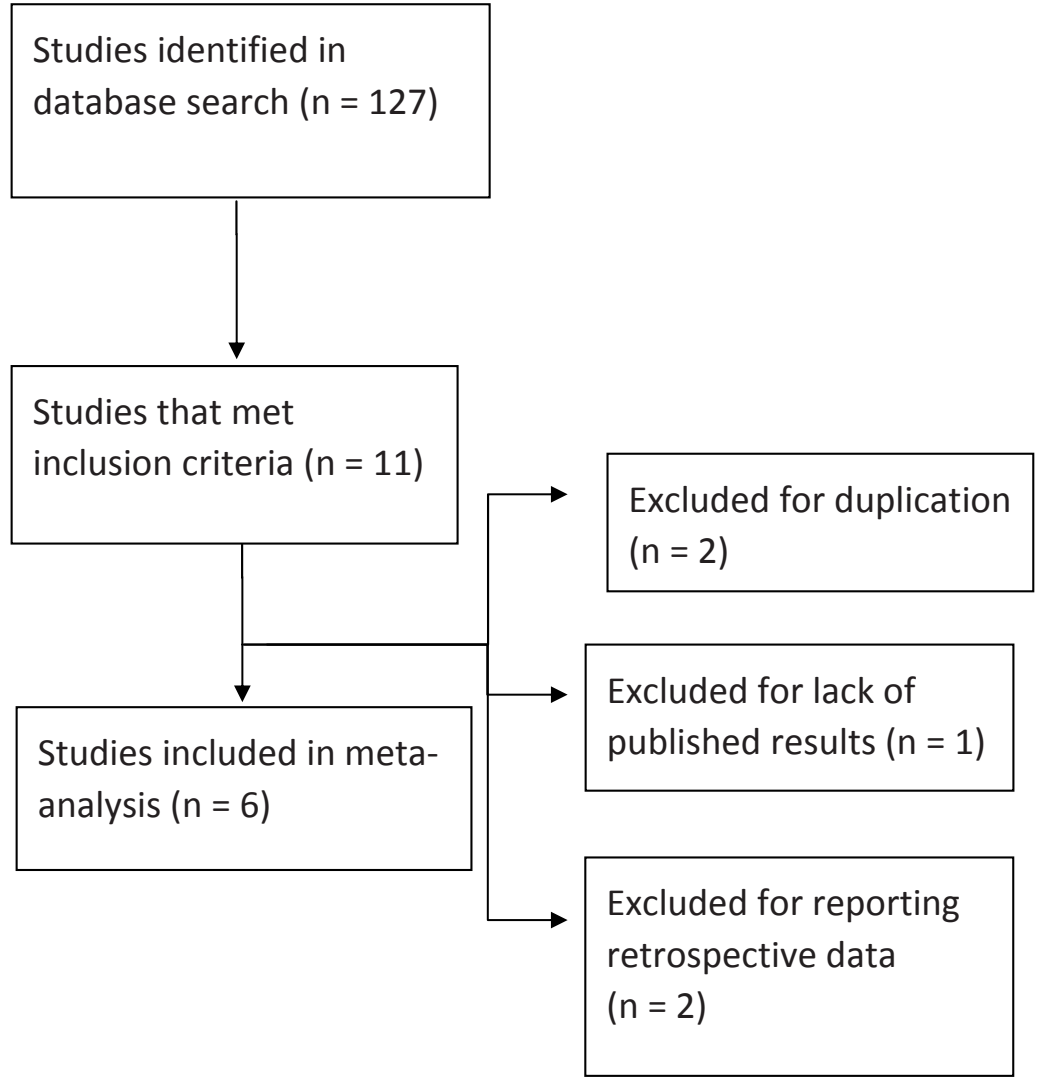


One trial performed conventional external beam radiation therapy, while all the others used 3D conformal radiation. None of them used intensity-modulated radiation. Radiation doses varied slightly between trials, ranging from 65 Gy to 70 Gy.

Four studies recruited patients with both intermediate- and high-risk non-metastatic prostate cancer; one study also recruited low-risk patients; and one recruited only high-risk prostate cancer patients. Two studies recruited patients in the neoadjuvant setting, while four trials were performed only in the adjuvant indication. All trials evaluated androgen deprivation with LHRH analogues. The EORTC 22961 (Bolla et al.) performed androgen deprivation with triptorelin, while all other trials used goserelin.

Hormone suppression duration was highly variable among the trials, both in the control and experimental arms. For that reason, we classified the trials in three subgroups, according to the duration of blockade. Two studies compared a short-term blockade of less than 12 months with a long-term blockade of more than 12 months -these studies were classified as the Long vs. Short blockade subgroups. In two studies, both arms had duration of less than 12 months (subgroup Short vs. Shorter), while one study had both arms longer than 12 months blockade (subgroup Longer vs.
Long). Study characteristics are detailed in Table-1.

Two studies $(21,22)$ reported DFS data separately for intermediate- and high-risk disease. Pooled data from these two studies, stratified by risk group, is described below. No study separately reported overall survival results for each risk strata.

\section{Overall Survival}

Five studies reported data on $\operatorname{OS}(16,17,22$, 23). Only two trials presented statistically significant results favoring a longer androgen blockade. However, in our pooled analysis, we observed a significant OS benefit favoring longer blockade duration, with a hazard ratio of 0.84 (95\% CI, 0.74 - 0.96), with low heterogeneity $\left(\mathrm{I}^{2}=23 \%\right)$.

This benefit was not different among the three subgroups analyzed (Long vs. Short, Short vs. Shorter, and Longer vs. Long), with a negative test for subgroup differences ( $p=0.96)$. The complete pooled analysis is shown on Figure-2.

\section{Disease-free and disease-specific survival}

Five studies reported DFS. The pooled analysis for this endpoint resulted in a statistically significant benefit favoring the longer blockade, with a HR 0.74 (95\% CI, 0.62-0.89). However, there was important heterogeneity between trials for this endpoint $\left(\mathrm{I}^{2}=70 \%\right)$. This heterogeneity was

Table 1 - Study Characteristics.

\begin{tabular}{lcccccccccc}
\hline Author & Year & $\begin{array}{c}\text { Number }- \\
\text { Short Arm }\end{array}$ & $\begin{array}{c}\text { Number - } \\
\text { Long Arm }\end{array}$ & $\begin{array}{c}\text { Hormone } \\
\text { Blockade }\end{array}$ & $\begin{array}{c}\text { Short Arm } \\
\text { (months) }\end{array}$ & $\begin{array}{c}\text { Long Arm } \\
\text { (months) }\end{array}$ & Timing & $\begin{array}{c}\text { Risk Categories } \\
\text { Included }\end{array}$ & $\begin{array}{c}\text { Radiation } \\
\text { Dose (Gy) }\end{array}$ \\
\hline Horwitz & 2008 & 763 & 758 & Goserelin & 4 & 24 & Adjuvant & $\begin{array}{c}\text { Intermediate and } \\
\text { High }\end{array}$ & $65-70$ \\
Bolla & 2009 & 483 & 487 & Triptorelin & 6 & 36 & Adjuvant & $\begin{array}{c}\text { Intermediate and } \\
\text { High }\end{array}$ & 70 \\
Crook & 2009 & 194 & 184 & Goserelin & 3 & 8 & Neoadjuvant & $\begin{array}{c}\text { Low, Intermediate } \\
\text { and High }\end{array}$ & 66 \\
Denham & 2011 & 270 & 272 & Goserelin & 3 & 6 & Adjuvant & $\begin{array}{c}\text { Intermediate and } \\
\text { High }\end{array}$ & 66 \\
Armstrong & 2011 & 137 & 139 & Triptorelin & 4 & 8 & Neoadjuvant & $\begin{array}{c}\text { Intermediate and } \\
\text { High }\end{array}$ & Variable \\
Nabid & 2013 & 320 & 310 & Goserelin & 18 & 36 & Adjuvant & High & 70 \\
\hline
\end{tabular}


Figure 2 - Overall Survival - Pooled Analysis.

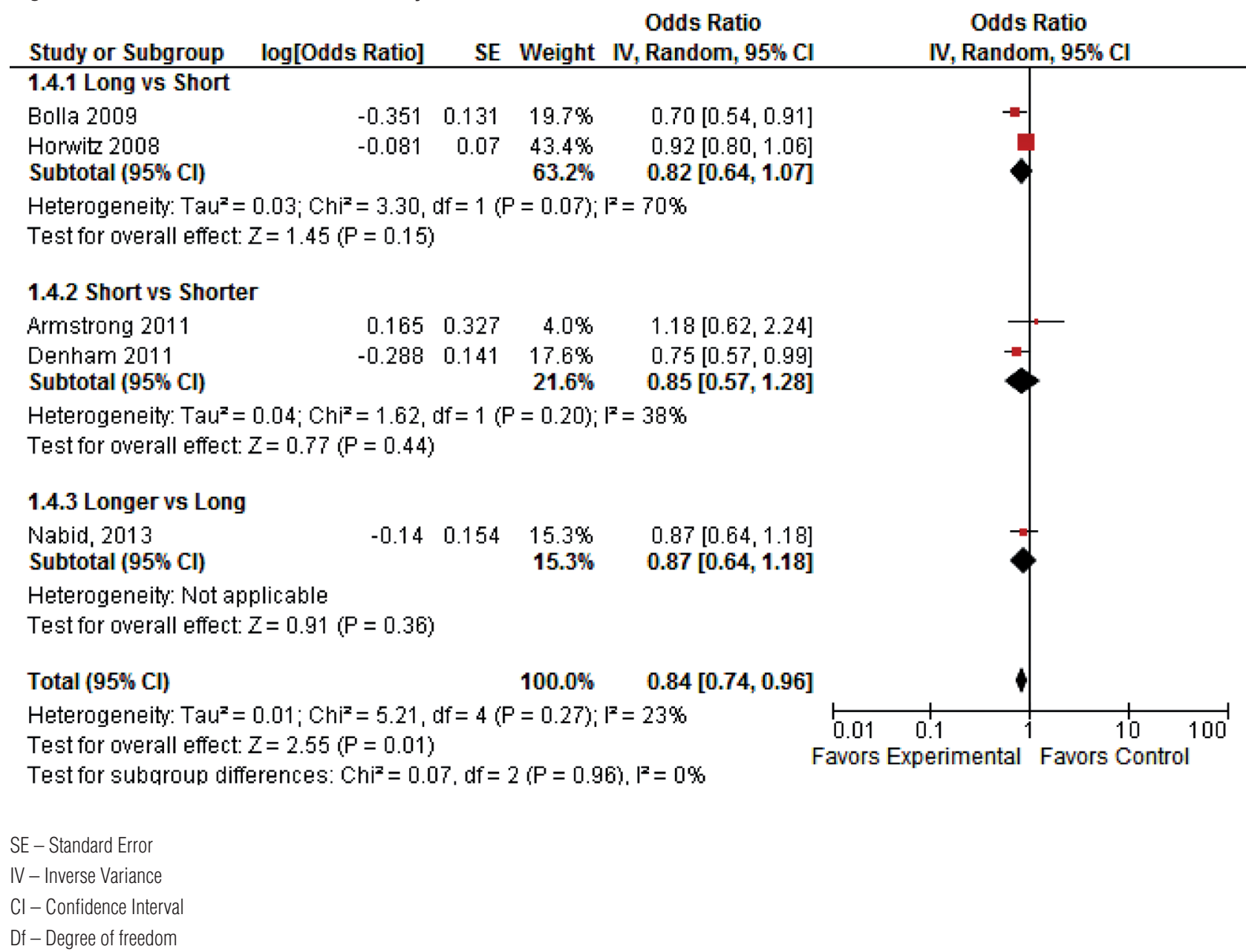

mainly due to a difference in study subgroups, with a positive test for interaction ( $\mathrm{p}=0.002)$. In the Long vs Short subgroup, there was a statistically significant benefit favoring the extended blockade treatment arm with a HR 0.63 (95\% CI, 0.56-0.71) and low heterogeneity within the subgroup $\left(I^{2}=11 \%\right)$. In the Short vs. Shorter only a non-significant trend favoring the extended hormone deprivation was observed (HR 0.86; 95\% CI, 0.76-1.02), also with low internal heterogeneity $\left(\mathrm{I}^{2}=2 \%\right)$. It is important to note that the two studies held in the neoadjuvant setting demonstrated no DFS benefit, with a HR 0.96 (95\% CI, 0.75-1.24) and no heterogeneity $\left(\mathrm{I}^{2}=0 \%\right)$. The complete pooled analysis is shown in Figure-3.

A subgroup analysis by risk stratification was performed using data from the two studies that reported DFS results separately for intermediate- and high-risk disease. Pooled data from these two studies shows a non-significant benefit for high-risk prostate cancer patients (HR 0.8; 95\% CI 0.56-1.15), with no heterogeneity between trials $\left(\mathrm{I}^{2}=0 \%\right)$. For intermediate-risk neoplasms, pooled data from these two studies also showed a non-significant trend favoring the longer blockade (HR 0.74; 95\% CI 0.36-1.55). For this subgroup of patients, however, heterogeneity between these two trials' results was high $\left(\mathrm{I}^{2}=73 \%\right)$. No obvious reasons were found to clearly justify this high heterogeneity between trials.

Disease-specific survival (DSS) was also reported in four trials $(16-18,23)$. Pooled data from these have shown a statistically significant benefit for the longer hormone deprivation with a 
Figure 3 - Disease-free Survival - Pooled Analysis.

\begin{tabular}{|c|c|c|c|c|c|c|}
\hline \multirow{2}{*}{$\frac{\text { Study or Subgroup }}{1.7 .1 \text { Long vs Short }}$} & log[Odds Ratio] & SE & Weight & $\begin{array}{l}\text { Odds Ratio } \\
\text { IV, Random, } 95 \% \mathrm{Cl}\end{array}$ & \multicolumn{2}{|c|}{$\begin{array}{l}\text { Odds Ratio } \\
\text { IV, Random, } 95 \% \mathrm{Cl}\end{array}$} \\
\hline & & & & & & \\
\hline Bolla 2009 & -0.571 & 0.12 & $20.8 \%$ & $0.56[0.45,0.71]$ & 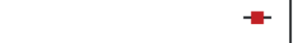 & \\
\hline Horwitz 2008 & -0.431 & 0.056 & $28.1 \%$ & $0.65[0.58,0.73]$ & 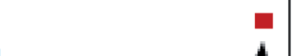 & \\
\hline Subtotal (95\% Cl) & & & $48.9 \%$ & $0.63[0.56,0.71]$ & 1 & \\
\hline \multicolumn{7}{|c|}{$\begin{array}{l}\text { Heterogeneity: } \operatorname{Tau}^{2}=0.00 ; \mathrm{Chi}^{2}=1.12, \mathrm{df}=1(\mathrm{P}=0.29) ; \mathrm{I}^{2}=11 \% \\
\text { Test for overall effect: } \mathrm{Z}=8.04(\mathrm{P}=0.00001)\end{array}$} \\
\hline \multicolumn{7}{|c|}{ 1.7.2 Short vs Shorter } \\
\hline Armstrong 2011 & 0.094 & 0.195 & $13.5 \%$ & $1.10[0.75,1.61]$ & & 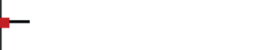 \\
\hline Crook 2009 & -0.142 & 0.175 & $15.1 \%$ & $0.87[0.62,1.22]$ & $=-1$ & \\
\hline $\begin{array}{l}\text { Denham } 2011 \\
\text { Subtotal }(95 \% \mathrm{Cl})\end{array}$ & -0.223 & 0.105 & $\begin{array}{l}22.5 \% \\
51.1 \%\end{array}$ & $\begin{array}{l}0.80[0.65,0.98] \\
0.86[0.73,1.02]\end{array}$ & 4 & \\
\hline \multicolumn{7}{|c|}{$\begin{array}{l}\text { Heterogeneity: } \text { Tau }^{2}=0.00 ; \mathrm{Chi}^{2}=2.05, \mathrm{df}=2(\mathrm{P}=0.36) ; \mathrm{I}^{2}=2 \% \\
\text { Test for overall effect: } \mathrm{Z}=1.77(\mathrm{P}=0.08)\end{array}$} \\
\hline Total $(95 \% \mathrm{Cl})$ & & & $100.0 \%$ & $0.74[0.62,0.89]$ & $\boldsymbol{\varphi}$ & \\
\hline \multicolumn{5}{|c|}{$\begin{array}{l}\text { Heterogeneity: Tau } \mathrm{u}^{2}=0.03 ; \mathrm{Ch}^{\mathrm{z}}=13.31, \mathrm{df}=4(\mathrm{P}=0.010) ; \mathrm{I}^{2}=70 \% \\
\text { Test for overall effect: } \mathrm{Z}=3.15(\mathrm{P}=0.002) \\
\text { Test for subaroup differences: } \mathrm{Ch}^{2}=9.56, \mathrm{df}=1(\mathrm{P}=0.002), \mathrm{I}^{\mathrm{z}}=89.5 \%\end{array}$} & \begin{tabular}{cc|}
0.01 & 0.1 \\
Favors experimental
\end{tabular} & ${ }_{\text {Favors control }}^{10} 100$ \\
\hline $\begin{array}{l}\text { SE - Standard Error } \\
\text { V - Inverse Variance } \\
\text { CI - Confidence Interval } \\
\text { Df - Degree of freedom }\end{array}$ & & & & & & \\
\hline
\end{tabular}

HR 0.73 (95\% CI, 0.62-0.85). Heterogeneity between trials for DSS was low $\left(\mathrm{I}^{2}=8 \%\right)$. Results for this endpoint are detailed in Figure-4.

Toxicity

Four studies reported information on toxicity $(16,17,22,23)$. None of them reported systematically the number of occurrences for each AE. Therefore, a pooled analysis was not possible. Also, authors of different studies reported the observed AEs in different ways. Hot flashes and diarrhea were the most frequently reported events. Data regarding cardiovascular events was reported in the RTOG 92.02 and EORTC 22961 trials, and neither found a statistically significant difference in cardiac events.

\section{DISCUSSION}

Despite the marked differences in androgen blockade duration evaluated in the trials, our pooled analysis showed an OS benefit for longer androgen deprivation. Such benefit was consistent between study subgroups. When considering DFS, however, the benefit observed in the pooled analysis was mostly due to the studies in the Long vs Short subgroup, while the Short vs. Shorter subgroup demonstrated only a non-significant trend toward an advantage. The unique study that compared two arms with longer-than-one-year hormone deprivation did not show any statistically significant difference in OS or DSS survival. However, with a HR 0.87 for OS favoring the longer blockade, its results were consistent with the other studies, and contributed to a statistically significant benefit in the pooled analysis. Also, the trial did not have a non-inferiority design, with no pre-specified boundary for assuming the HR as clinically irrelevant. Therefore, it may not yet be considered safe to reduce the standard treatment duration from 2-3 years to 18 months in current clinical practice. A large, randomized, 
Figure 4 - Disease-specific Survival - Pooled Analysis.

\begin{tabular}{|c|c|c|c|c|c|c|}
\hline Study or Subgroup & log[Odds Ratio] & SE & Weight & $\begin{array}{c}\text { Odds Ratio } \\
\text { IV, Random, } 95 \% \mathrm{CI}\end{array}$ & $\begin{array}{r}\text { Odds } \\
\text { IV, Randor }\end{array}$ & $\begin{array}{l}\text { Ratio } \\
\mathrm{m}, 95 \% \mathrm{Cl}\end{array}$ \\
\hline Bolla 2009 & -0.532 & 0.206 & $14.1 \%$ & $0.59[0.39,0.88]$ & $\rightarrow-$ & \\
\hline Denham 2011 & -0.223 & 0.105 & $47.3 \%$ & $0.80[0.65,0.98]$ & 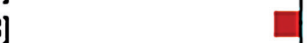 & \\
\hline Horwitz 2008 & -0.42 & 0.135 & $30.7 \%$ & $0.66[0.50,0.86]$ & $=$ & \\
\hline Nabid, 2013 & -0.069 & 0.278 & $7.9 \%$ & $0.93[0.54,1.61]$ & & . \\
\hline Total $(95 \% \mathrm{Cl})$ & & & $100.0 \%$ & $0.73[0.62,0.85]$ & $\checkmark$ & \\
\hline \multicolumn{5}{|c|}{$\begin{array}{l}\text { Heterogeneity: } \text { Tau }^{2}=0.00 ; \text { Chi }^{2}=3.26, d f=3(P=0.35) ; l^{2}=8 \% \\
\text { Test for overall effect: } Z=3.97(P<0.0001)\end{array}$} & $\begin{array}{cc}0.01 & 0.1 \\
\text { Favors experimental }\end{array}$ & $1 \underset{10}{10} 100$ \\
\hline $\begin{array}{l}\text { SE - Standard Error } \\
\text { IV - Inverse Variance } \\
\mathrm{Cl} \text { - Confidence Interval } \\
\text { Df - Degree of freedom }\end{array}$ & & & & & & \\
\hline
\end{tabular}

non-inferiority trial should be performed to test this approach.

The two larger studies $(16,17)$ demonstrated quite different results with respect to OS. While Bolla and colleagues have reported an important benefit for the longer blockade in terms of OS in the European EORTC 22961 trial, Horwitz and colleagues found no statistically significant difference in the American RTOG 92.02 study. Inclusion criteria, radiation dose, and patient characteristics were similar between the two trials, so there is no obvious explanation for such a discrepancy between their results. One should note that the European trial used a longer androgen deprivation (36 months) than the American study (24 months). Patients with recurrent prostate cancer can have a relatively good overall survival, especially when compared to other recurrent or metastatic neoplasms (24). Also, prostate cancer patients tend to be elderly and many of them have important comorbidities and competitive risks of death (25). For these reasons, a benefit in terms of DFS or DSS may not necessarily translate into an OS benefit. When considering the two larger randomized trials, it is important to observe that they are consistent in showing a DFS and DSS benefit, despite their discordant results with regard to OS. In fact, DSS was the endpoint with the most consistent positive results among all trials evaluated.
Regarding comparison between shorter duration of androgen deprivation, two studies, the TROG 96.01 by Denham et al. and the Irish Clinical Oncology Group 97-01 by Armstrong and colleagues, reported OS data from randomized trials. The trials compared two arms with less than 12 months of androgen deprivation each. They demonstrated an important discrepancy in results: Denham and colleagues demonstrated a DFS and OS benefits while Armstrong and colleagues demonstrated no benefit in any endpoint. There were, however, important differences between these trial designs. In the TROG trial, patients received hormone blockade after radiation therapy, while in the Irish trial, hormonal deprivation was performed in the neoadjuvant setting. Though previous trials have shown benefit of hormone blockade prior to radiation therapy versus radiation therapy alone (10), there is no previous evidence suggesting that a longer neoadjuvant blockade bears additional benefit. Data from pooled analysis of the studies by Crook and colleagues and Armstrong and colleagues, both performed in the neoadjuvant scene, demonstrated no DFS benefit for the longer androgen deprivation. So, extending hormonal therapy before local control may not be recommended, once long-term therapy can be delivered after prostate irradiation and a longer neoadjuvant therapy could delay local control (26). 
The unique study that included low-risk prostate cancer patients did not show any DFS benefit. There is no consistent evidence that adjuvant hormone therapy provides benefit in such a good prognosis subgroup, so including those patients in long-term blockade trials may not be recommended (3). Most other trials have included both intermediate- and high-risk cancer patients, so it is not yet possible to establish a difference in the recommended treatment strategy between these groups. Data on subgroups of the two largest trials evaluated in this systematic review (RTOG 92-02 and EORTC 22961) has not been published, leading to a reduction in the power of this analysis. The pooled data from the Irish and Canadian trials may not be enough to establish if intermediate-risk patients benefit from treatment as much as high-risk ones do. No prospective randomized trial has addressed the specific question of whether hormone deprivation therapy duration could be reduced in the intermediate-risk group. However, there is some evidence from subgroup analysis and retrospective studies that extending androgen blockade bears a greater benefit for high-risk patients than for the intermediate-risk ones.

Androgen deprivation is associated with important AEs like loss of bone density, erectile dysfunction, and hot flushes $(14,27)$. However, such AEs are usually manageable and almost never fatal. Hormonal therapy has been associated with increased cardiovascular risks in observational studies, including an increased risk of obesity, diabetes, myocardial infarction, and cardiac sudden death (15). However, it has not been demonstrated that hormone deprivation significantly increases mortality from cardiac causes, with reports from several trials demonstrating no difference in risk of cardiovascular death $(8,28$, 29). In this systematic review we didn't find any evidence suggesting an increase in cardiovascular risk for patients treated with long-term adjuvant hormone deprivation.

\section{CONCLUSIONS}

Given the OS benefit and generally favorable toxicity profile, extended duration adjuvant hormone blockade may be recommended after radiation therapy for intermediate- and high-risk non-metastatic prostate cancer. However, it is important to note that the evidence is based on trials using older radiation techniques. There is a need of new studies, with non-inferiority design, evaluating different durations of androgen deprivation in patients with intermediate- and high-risk non-metastatic prostate cancer receiving modern radiation therapy.

\section{ACKNOWLEDGEMENT}

The authors thank Deborah Salerno for her kind support with grammar and style.

\section{FUNDING}

The authors received no funding for this research.

\section{CONFLICT OF INTEREST}

None declared.

\section{REFERENCES}

1. Potosky AL, Davis WW, Hoffman RM, Stanford JL, Stephenson RA, Penson DF, et al. Five-year outcomes after prostatectomy or radiotherapy for prostate cancer: the prostate cancer outcomes study. J Natl Cancer Inst. 2004;96:1358-67.

2. Resnick MJ, Koyama T, Fan KH, Albertsen PC, Goodman $M$, Hamilton AS, et al. Long-term functional outcomes after treatment for localized prostate cancer. N Engl J Med. 2013;368:436-45.

3. D'Amico AV, Moul J, Carroll PR, Sun L, Lubeck D, Chen MH. Cancer-specific mortality after surgery or radiation for patients with clinically localized prostate cancer managed during the prostate-specific antigen era. J Clin Oncol. 2003;21:2163-72.

4. Westover K, Chen MH, Moul J, Robertson C, Polascik T, Dosoretz D, et al. Radical prostatectomy vs radiation therapy and androgen-suppression therapy in high-risk prostate cancer. BJU Int. 2012;110:1116-21.

5. Bolla M, Gonzalez D, Warde P, Dubois JB, Mirimanoff RO, Storme $\mathrm{G}$, et al. Improved survival in patients with locally advanced prostate cancer treated with radiotherapy and goserelin. N Engl J Med. 1997;337:295-300. 
6. Lawton CA, Winter K, Grignon D, Pilepich MV. Androgen suppression plus radiation versus radiation alone for patients with stage D1/pathologic node-positive adenocarcinoma of the prostate: updated results based on national prospective randomized trial Radiation Therapy Oncology Group 85-31. J Clin Oncol. 2005;23:800-7. Erratum in: J Clin Oncol. 2005;23:8921.

7. Bolla M, Van Tienhoven G, Warde P, Dubois JB, Mirimanoff R0, Storme G, et al. External irradiation with or without long-term androgen suppression for prostate cancer with high metastatic risk: 10-year results of an EORTC randomised study. Lancet Oncol. 2010;11:1066-73.

8. Roach M 3rd, Bae K, Speight J, Wolkov HB, Rubin P, Lee RJ, et al. Short-term neoadjuvant androgen deprivation therapy and external-beam radiotherapy for locally advanced prostate cancer: long-term results of RTOG 8610. J Clin Oncol. 2008;26:585-91.

9. Sasse AD, Sasse E, Carvalho AM, Macedo LT. Androgenic suppression combined with radiotherapy for the treatment of prostate adenocarcinoma: a systematic review. BMC Cancer. 2012;12:54.

10. Shelley MD, Kumar S, Wilt T, Staffurth J, Coles B, Mason MD. A systematic review and meta-analysis of randomised trials of neo-adjuvant hormone therapy for localised and locally advanced prostate carcinoma. Cancer Treat Rev. 2009;35:9-17.

11. Mottet N, Peneau M, Mazeron JJ, Molinie V, Richaud P. Addition of radiotherapy to long-term androgen deprivation in locally advanced prostate cancer: an open randomised phase 3 trial. Eur Urol. 2012;62:213-9.

12. Warde $P$, Mason $M$, Ding $K$, Kirkbride $P$, Brundage $\mathrm{M}$, Cowan R, et al. NCIC CTG PR.3/MRC UK PR07 investigators. Combined androgen deprivation therapy and radiation therapy for locally advanced prostate cancer: a randomised, phase 3 trial. Lancet. 2011;378:2104-11.

13. McLeod DG, Iversen P, See WA, Morris T, Armstrong J, Wirth MP; Casodex Early Prostate Cancer Trialists' Group. Bicalutamide $150 \mathrm{mg}$ plus standard care vs standard care alone for early prostate cancer. BJU Int. 2006;97:247-54.

14. Basaria S, Lieb J 2nd, Tang AM, DeWeese T, Carducci $M$, Eisenberger $M$, et al. Long-term effects of androgen deprivation therapy in prostate cancer patients. Clin Endocrinol (Oxf). 2002;56:779-86.

15. Keating NL, O'Malley AJ, Freedland SJ, Smith MR. Diabetes and cardiovascular disease during androgen deprivation therapy: observational study of veterans with prostate cancer. J Natl Cancer Inst. 2010;102:39-46.
16. Horwitz EM, Bae K, Hanks GE, Porter A, Grignon DJ, Brereton $H D$, et al. Ten-year follow-up of radiation therapy oncology group protocol 92-02: a phase III trial of the duration of elective androgen deprivation in locally advanced prostate cancer. J Clin Oncol. 2008;26:2497-504.

17. Bolla M, de Reijke TM, Van Tienhoven G, Van den Bergh AC, Oddens J, Poortmans PM, et al. EORTC Radiation Oncology Group and Genito-Urinary Tract Cancer Group. Duration of androgen suppression in the treatment of prostate cancer. N Engl J Med. 2009;360:2516-27.

18. Nabid A, Carrier N, Martin A-G, Bahary J-P, Souhami L, et al. (2013) High-risk prostate cancer treated with pelvic radiotherapy and 36 versus 18 months of androgen blockade: Results of a phase III randomized study. In: ASC0, editor. 2013 Genitourinary Cancers Symposium: ASCO.

19. Tierney JF, Stewart LA, Ghersi D, Burdett S, Sydes MR. Practical methods for incorporating summary time-toevent data into meta-analysis. Trials. 2007;8:16.

20. Higgins JP, Thompson SG, Deeks JJ, Altman DG. Measuring inconsistency in meta-analyses. BMJ. 2003;327:557-60.

21. Crook J, Ludgate C, Malone S, Perry G, Eapen L, Bowen $J$, et al. Final report of multicenter Canadian Phase III randomized trial of 3 versus 8 months of neoadjuvant androgen deprivation therapy before conventional-dose radiotherapy for clinically localized prostate cancer. Int J Radiat Oncol Biol Phys. 2009;73:327-33.

22. Armstrong JG, Gillham CM, Dunne MT, Fitzpatrick DA, Finn MA, Cannon ME, et al. A randomized trial (Irish clinical oncology research group 97-01) comparing short versus protracted neoadjuvant hormonal therapy before radiotherapy for localized prostate cancer. Int $\mathrm{J}$ Radiat Oncol Biol Phys. 2011;81:35-45.

23. Denham JW, Steigler A, Lamb DS, Joseph D, Turner S, Matthews J, et al. Short-term neoadjuvant androgen deprivation and radiotherapy for locally advanced prostate cancer: 10-year data from the TROG 96.01 randomised trial. Lancet Oncol. 2011;12:451-9.

24. Halabi S, Small EJ, Kantoff PW, Kattan MW, Kaplan EB, Dawson NA, et al. Prognostic model for predicting survival in men with hormone-refractory metastatic prostate cancer. J Clin Oncol. 2003;21:1232-7. Erratum in: J Clin Oncol. 2004;22:3434.

25. Newschaffer CJ, Otani K, McDonald MK, Penberthy LT. Causes of death in elderly prostate cancer patients and in a comparison nonprostate cancer cohort. J Natl Cancer Inst. 2000;92:613-21. 
26. Bolla M, Collette L, Blank L, Warde P, Dubois JB, Mirimanoff $\mathrm{RO}$, et al. Long-term results with immediate androgen suppression and external irradiation in patients with locally advanced prostate cancer (an EORTC study): a phase III randomised trial. Lancet. 2002;360:103-6.

27. Higano CS. Side effects of androgen deprivation therapy: monitoring and minimizing toxicity. Urology. 2003;61:32-8.

28. Efstathiou JA, Bae K, Shipley WU, Hanks GE, Pilepich MV, Sandler HM, et al. Cardiovascular mortality after androgen deprivation therapy for locally advanced prostate cancer: RTOG 85-31. J Clin Oncol. 2009;27:92-9.
29. Efstathiou JA, Bae K, Shipley WU, Hanks GE, Pilepich MV Sandler HM, et al. Cardiovascular mortality and duration of androgen deprivation for locally advanced prostate cancer: analysis of RTOG 92-02. Eur Urol. 2008;54:816-23.

Correspondence address:

Andre Deeke Sasse, MD, PhD

Centre for Evidence in Oncology (CEVON), Depart. of Int. Medicina, Faculdade de Ciências médicas, Universidade Estadual de Campinas (UNICAMP), Vital Brasil 251, Campinas, SP, 13083-888, Brasil Fax: +55 19 3521-8345 E-mail: sasse@cevon.com.br 